\title{
Construcción y deconstrucción del converso a través de los memoriales de limpieza de sangre durante el reinado de Felipe III*
}

\author{
Juan Hernández Franco, Antonio Irigoyen López ** \\ Universidad de Murcia
}

En este artículo ponemos de relieve cómo el gran momento de la reforma de los estatutos de limpieza de sangre, que tendrá lugar en la segunda década del siglo XVII, tiene un destacado e intenso prolegómeno, que se fecha a partir del último tercio del Quinientos. En un ambiente mayoritariamente partidario de la ideología de los cristianos viejos y su propósito de excluir a los conversos de los honores sociales, tímidamente tanto Felipe II, en sus últimos años de vida, como Felipe III, la Inquisición y en concreto inquisidores generales como Quiroga, Niño de Guevara y Rojas, o bien sobresalientes religiosos como Rivadeneira, de las Casas y Montemayor, van a dar su apoyo en unos casos y a revisar en otros la conducta con la que se asocia al converso. Los últimos harán hincapié en su condición de cristianos auténticos y las ventajas que reportaban sus conocimientos y formación para la sociedad y sus instituciones.

Palabras Clave: Estatutos de limpieza de sangre; exclusión social; intolerancia; cristianos viejos; conversos; identidad socio-religiosa.

* Este trabajo forma parte del proyecto de investigación 15300/PHCS/10 Nobilitas. Estudios y base documental de la nobleza del Reino de Murcia, siglos XV-XIX. Segunda fase: análisis comparativos, financiado por la Fundación Séneca: Agencia regional de Ciencia y Tecnología de la Región de Murcia; del proyecto de investigación 11863/ PHCS/09: El legado de los sacerdotes. El patrimonio del clero secular en Castilla durante el Antiguo Régimen, financiado por la Fundación Séneca; y del proyecto HAR200914034-CO2: Estrategias de tolerancia y políticas públicas. Antisemitismo, islamofobia y cristianofobia. Aspectos históricos, jurídicos y culturales.

**.jhf@um.es, adiri@um.es 
Construction and Deconstruction of the Image of the Converso through Purity of Blood Memorandums during the Reign of Philip III.- In this article we wish to emphasize that the great moment of the reform of the Purity of blood statutes, situated in the second decade of the $17^{\text {th }}$ century, had prominent and intense antecedents from the last third of the $16^{\text {th }}$ century through the first decades of the $17^{\text {th }}$ seventeenth century. Although there was a majority in favour of the Cristianos Viejos' ideology and their aim to exclude Conversos from all social honours, both Philip II, during the last years of his life, as well as Philip III, timidly espoused a rehabilitation of the Converso image. Along with the two monarchs, Inquisitors General such as Quiroga, Niño de Guevara and Rojas, and outstanding religious figures, such as Rivadaneira, de las Casas and Montemayor, gave their support to a revision of the behavioural image associated with Conversos. These clergymen propounded that the latter had achieved authentic Christian status. Moreover, they believed that Conversos possessed skills and training potentially beneficial to society at large and its institutions.

KeYwords: Purity of Blood Statutes; Social Exclusion; Intolerance; Old Christians; Conversos; Socio-religious Identity.

Hacia mediados del siglo XVI, en la sociedad castellana se había construido una identidad despreciable, denigrada y perversa del cristiano nuevo ${ }^{1}$. A fin de cuentas era la continuación de la imagen negativa que se tenía del judío durante la Edad Media. Por esta razón, el arzobispo de Toledo, Juan Martínez Silíceo, tras aprobar el estatuto de la catedral, dejó sentado qué eran los cristianos nuevos: «enemigos de Dios» ${ }^{2}$. Esto servía para justificar su posición y también para rebatir a dos ilustres oponentes, el arcediano de Guadalajara y el arcediano de Talavera, hijos del duque del Infantado y miembros del linaje de los Mendoza. Según el arzobispo,

${ }^{1}$ Valga como ejemplo las narraciones tradicionales que se dieron en la Península Ibérica: J. M. Monsalvo Antón, Teoría y evolución de un conflicto social. El antisemitismo en la corona de Castilla en la Baja Edad Media (Madrid, 1985); J. M. Pedrosa, «El antisemitismo en la cultura popular española», en G. Álvarez Chillida, R. Izquierdo Benito, coords., El antisemitismo en España (Cuenca, 2007), 31-55; E. Cantera Montenegro, «La imagen del judío como prototipo del mal en la Edad Media», en A. I. Carrasco Manchado et al., Pecar en la Edad Media (Madrid, 2008), 297-326; A. Alba, C. Sainz de la Maza, «Señas de identidad judías y cristianas en la cuentística medieval: algunos ejemplos hispánicos», Sefarad 72 (2012), 145-190.

${ }^{2}$ Biblioteca Nacional de España [= BNE], Ms. 9175. Respuesta de Juan Martínez Silíceo al requerimiento sobre el estatuto de limpieza efectuado por Pedro González. de Mendoza, arcediano de Guadalajara, y Álvaro de Mendoza, arcediano de Talavera (Toledo, 1547). 
todo procedía del linaje, pues la sangre heredada por los recién cristianizados, los convertía en descendientes de quienes fueron responsables del magno pecado del deicidio; lo que se añadía a los vicios propios de la condición judía. Además estaba su propia actitud personal como cristianos, ya que no seguían la verdadera religión, sino que apostataban y llevaban a cabo actos heréticos. Aunque si espigamos en otros documentos que el propio Juan Martínez Silíceo y sus partidarios escriben con motivo de argumentar a favor de los estatutos, también nos encontramos con causas humanas, terrenales, pues los recién convertidos asimismo eran enemigos sociales puesto que disputaban con el cristiano viejo -valor aún no asociado al de noble- los puestos con honor y distinción en una época de movilidad social ${ }^{3}$.

En fin, como escribía un año después, 1548, el bachiller Pedro Ortiz, procurador fiscal del Santo Oficio de Toledo, los cristianos nuevos eran hombres que «habían de ser aborrecidos y amenguados conforme a derecho» ${ }^{4}$.

Sin embargo, esta decisión de repeler al cristiano nuevo del mundo del honor y de las instituciones importantes, comienza a remitir a partir de la penúltima década del siglo XVI. Previamente, varias voces de forma aislada y sin mucho eco social, se habían alzado contra los estatutos y sus consecuencias. Pero desde la fecha citada, la Corona, personas cercanas al rey -como, por ejemplo, el cardenal de Toledo e inquisidor general Quiroga, conocido en su juventud por apoyar el estatuto de Silíceo, y luego cambiar de actitud tanto por sus propias convicciones en materia religiosa, como por su relación con los padres españoles de la Compañía

\footnotetext{
${ }^{3}$ Destacamos entre las últimas publicaciones sobre esta cuestión, M. MARTínEZ MiLláN, «Nobleza hispana, nobleza cristiana: los estatutos de limpieza de sangre», en M. Rivero RodRíGUEz, coord., Nobleza hispana, nobleza cristiana: la orden de San Juan (Madrid, 2009), vol. I, 677-758; M. Escamilla, «La polémique autour de la pratique du statut de pureté de sang», en R. CARrasco, A. Molinié, B. Pérez, dirs., La pureté de sang en Espagne. Du lignage à la race (Paris, 2011), 49-80; F. QuERO, «Le statut de pureté de sang de Tolède et l'identité de vieux-chrétiens», en CARrasco, Molinié, Pérez, dirs., La pureté de sang en Espagne. Du lignage à la race, 187-203; J. HeRnÁndez Franco, Sangre limpia, sangre española. El debate de los estatutos de limpieza (siglos XV-XVII) (Madrid, 2011).

${ }^{4}$ Archivo Histórico Nacional [= AHN], Inquisición, leg. 120, núm 9, proceso contra Juan Rodríguez de Pisa, vecino de El Viso, 1549, citado en R. CARRASCO, «Pureté de sang et paix civile en Nouvelle Castille (xv-Xvi siècle)», en J. Battesti-Pelegrin, ed., Qu'un sang impur... Les conversos et le pouvoir en Espagne à la fin du Moyen Âge (Aix-enProvence, 1997), 61-87: 85.
} 
de Jesús ${ }^{5}$, lo que le lleva a oponerse al estatuto que establece la orden en 1593 y decir que «en lugar de ganar honra, se ha la Compañía deshonrado con este decreto cerrando la puerta no solo a los sacerdotes» ${ }^{6}-$, algunos representantes del Reino y religiosos, comienzan a solicitar la reforma de los estatutos de limpieza: se comienza a revisar y cuestionar la identidad maldita que se había imputado al converso.

Lo que hemos percibido es que, a diferencia de lo que proponía Sicroff, quien marcaba que el gran momento de la reforma estatutaria tuvo lugar en los años veinte del siglo XVII, hay una intensa etapa precedente en la que se revisa tanto la conveniencia de los estatutos como la condición del converso. Tuvo una notable repercusión, pues, el posicionamiento favorable a la reforma de los estatutos que adoptó el gran patrón cortesano, el cardenal Quiroga -algo que con posterioridad recordaran los tratadistas partidarios de la reformas-, que coincidiría con las renovadoras propuestas de Gaspar de Uceda, de los jesuitas castellanos o del predicador real fray Agustín Salucio durante los últimos años del reinado de Felipe II. Éstas fueron las bases necesarias para que, durante el reinado de Felipe III, no se enfriase la actitud revisionista y, en consecuencia, se propusieran notorios, y apenas conocidos, planes reformistas sobre la identidad del converso. Analizar estos escritos es, precisamente, el objetivo de este trabajo.

\section{LOS PRECEDENTES DEL SIGLO XVI}

En 1586, el franciscano fray Gaspar de Uceda escribe el Tratado donde se ponen algunas razones y fundamentos contra el Statuto que en la Congregación General de Toledo hizieron los frailes menores el año de mil y quinientos y ochenta y tres donde se ordenó que ningún descendiente de judio, sarrazeno o hereje sea reçebido a la Orden ${ }^{7}$. Defiende

\footnotetext{
${ }^{5}$ H. Pizarro Llorente, Un gran patrón en la corte de Felipe II. Don Gaspar de Quiroga (Madrid, 2004), 49-65 y 100-107.

${ }^{6}$ F. DE B. Medina, «Precursores de Vieira: Jesuitas andaluces y castellanos a favor de los cristianos nuevos», en Terceiro Centenário da morte do padre António Vieira. Congresso Internacional (Braga, 1999), vol. I, 491-519: 499.

${ }^{7}$ BNE, Ms. 6371, y Biblioteca Colegio Mayor Santa Cruz, Valladolid, Ms. 475. Empleamos el excelente estudio y trascripción del tratado que ha efectuado E. PérEz FERREIRo, El tratado de Uceda contra los estatutos de limpieza de sangre (Madrid, 2000). Citaremos de acuerdo con la paginación de esta edición.
} 
con ardor la necesaria limitación en la averiguación del linaje y considera que los estatutos, tal como se están aplicando, son «yllícitos e contienen mucha parte de injusticia».

Especialmente claro es su juicio contra los cristianos viejos, ya que con el establecimiento de los estatutos, han convertido la limpieza de linaje en un instrumento que les ha permitido alcanzar honras y oficios por razón de la herencia de una sangre sin mácula, y no por virtud o preparación. Ahora bien, expuesto esto, hay que indicar que su propuesta no es anti-estatutaria; sólo pretende que la religión católica y la propia orden de San Francisco no resulten dañadas por la aplicación de los estatutos. Indica que los estatutos no son un «error», que la exclusión que realizan debe reducirse a casos individuales de conversos que han cometido apostasía, y que las instituciones particulares (colegios mayores) pueden establecerlos, si sus fundadores los consideraban oportunos.

A Uceda le preocupan los estatutos - como acabamos de indicar- por los perjuicios o «estorbos» que originan a la religión católica y a la orden de los franciscanos menores. En concreto a la religión católica por tres causas:

1) Los estatutos se alejan de la tradición ecuménica que ha caracterizado al credo cristiano. Dios no ha querido que existan diferencias de linaje: «Dios no hace diferencias entre el judío y el gentil, no la hagáis entre vosotros mismos. Un mismo señor tenéis que es Señor de todos»; en cambio Dios sí quiere que todos vivan bajo la misma ley, «porque viviendo todos debajo de una ley tuviesen más ocasión de vivir en paz y sosiego».

2) Los estatutos están produciendo dentro de la congregación cristiana «discordia», «disensión» o «szima» (cisma) entre los descendientes de los gentiles y los descendientes de los judíos por el «solo título del linaje». De este hecho responsabiliza a los cristianos viejos por sus ambiciones, por su pasión, por considerar superior el tronco o linaje del que provienen.

3) Los estatutos, al excluir al que no posee un origen cristiano viejo, dificultan que los que profesan credos diferentes quieran abrazar la fe católica; por tanto, no estimula a que los conversos progresen o aumenten en su fe. 
Por lo que respecta a los perjuicios que los estatutos originan a la orden en la que profesa Uceda, señala que los franciscanos menores, al establecer la norma, han distorsionado el espíritu con que Francisco de Asís la creó. Si la regla de San Francisco pretende que los regulares se mantuvieran en la perfección evangélica y alcanzasen la vida eterna, el estatuto establecido no permite vivir la fe gobernados por la penitencia y por el auténtico dogma ${ }^{8}$. La conclusión es clara y se halla en el objetivo fundamental de la obra que se encuentra al final:

persuadir se debe moderar y limitar un Estatuto ordenado por los superiores de la Orden del bienaventurado padre San Francisco?

Pero las ideas de Uceda eran avanzadas, o por lo menos, no eran opinión corriente, en unos momentos de rigor estatutario y de rigor religioso dentro de la sociedad castellana. Por esta razón, no puede extrañar que, tras su publicación, la Inquisición ordenase su recogida.

Cuando a finales del año 1593, la Compañía de Jesús establezca estatutos de limpieza de sangre, Pedro de Rivadeneira (1526-1611), superior de la Compañía, advertirá sobre los perjuicios que esta decisión supondrá. Este jesuita, historiador, tratadista político e hijo de padres conversos por ambas líneas, expondrá en carta escrita con motivo de las Congregaciones Generales V y VI las razones -en total trece- por las «que no hazer novedad en el admitir gente en la Compañía» ${ }^{10}$.

Rivadeneira enlaza con una línea de pensamiento que había caracterizado a la Compañía desde su fundación en 1540. Los primeros generales, comenzando por Ignacio de Loyola y continuando con Laínez y Francisco de Borja, se mostraron en contra de la exclusión del cristiano nuevo. Junto a ello, las Constituciones de la Compañía no establecían exclusión u otro tipo de impedimento por la sangre o «generación». Sin embargo, la presión de los jesuitas de nacionalidad portuguesa, y algunos españoles e italianos, fue tenida en cuenta

\footnotetext{
${ }^{8}$ Pérez Ferreiro, El tratado de Uceda, 65-114.

${ }^{9}$ Pérez Ferreiro, El tratado de Uceda, 153.

${ }^{10}$ Confessiones, Epistolae aliaque Scripta inedita ex autographis, antiquissimis apographis et regestis deprompta (patris Petri de Ribadeneira S. J.) (Madrid, 1920-23). En concreto trata el problema de la limpieza de sangre en la epístola 14, titulada De prognatis genere hebraeorum Societatis aditun non excludendis (Madrid, 1593).
} 
por el general Acquaviva, que acaba permitiendo la exclusión de «los notados en su linaje» ${ }^{11}$.

Las reflexiones y argumentos de Pedro de Rivadeneira pretendían impedir el establecimiento del estatuto, algo que no tuvo éxito. Entre las razones más sobresalientes, cuatro nos parecen de enorme relevancia y, en concreto, las tres últimas se volverán a citar cuando más adelante se intente reformar los estatutos.

- Primera: el espíritu seminal de la Compañía (la imitación a Cristo) sigue vivo entre los padres que más la aman y, como precisa Rivadeneira, cuando alguien recibe el llamamiento de Dios, «mucho menos la religión ha desechar al que llama Dios, por nasçer de agüelo o uisagüelo, que ahora ciento o ducientos años se convirtieron».

- Segunda: discernir entre «linages y sangre» provoca el caos, la división, el cisma y, en consecuencia, la debilidad de la institución, de forma que en «haçiendo estatuto se perderá, porque entrará el fuego de la discordia en ella, la división y guerra doméstica y entrañable».

- Tercera: la sangre y la estirpe no es el mal que perturba la paz en el interior de las instituciones, sino las actitudes personales: «de suerte que no se puede decir que es uiçio de linaje sino de las personas; pues hombres de varios linages han concurrido en esta turbación».

${ }^{11} \mathrm{El}$ análisis y contexto en que tiene lugar la controversia acerca del establecimiento de estatuto por parte de la Compañía de Jesús, ha sido analizada detalladamente por E. REY, «San Ignacio de Loyola y el problema de los cristianos nuevos», Razón y Fe 153 (1956), 178-204; J. W. ReITES, «St. Ignatius of Loyola and the Jews», Studies in the Spirituality of the Jesuits 13 (1981), 1-48; F. DE B. Medina, «Ignacio de Loyola y la limpieza de sangre», en Ignacio de Loyola y su tiempo (Bilbao, 1992), 579-615; A. Sicroff, Los estatutos de limpieza de sangre. Controversias entre los siglos XV y XVII (Madrid, 1979), 315-336; A. Domínguez OrTiz, La clase social de los conversos en Castilla en la edad moderna (Madrid, 1952), 152-154. Nuevas revisiones se pueden hallar en R. A. MARYKs, The Jesuit Order as a Synagogue of Jews. Jesuits of Jewish Ancestry and Purity-of-Blood Laws in the Early Society of Jesus (Leiden, 2009), 187-190, y E. JimÉNEZ PABLO, «Que por sus pies se avia venido a la pila... El decreto de limpieza de sangre en la Compañía de Jesús (1540-1608)», en Rivero RodríGuez, coord., Nobleza hispana, nobleza cristiana, vol. I, 759-794. 
- Cuarta, resulta lesivo para el funcionamiento de las instituciones poner la sangre y el linaje por encima de la formación, de la capacitación, de las «letras y prudencia» ${ }^{12}$.

En esta época, la posición de la Corona, y más concretamente de Felipe II, sobre los estatutos comienza a cambiar. El rey ya se había mostrado contrario al establecimiento de estatuto por parte de la Compañía de Jesús, haciéndoselo saber al general Acquaviva a través del jesuita Acosta, también de ascendencia conversa. En los últimos años de su gobierno, el monarca «con gran acuerdo de sus Consejos hubo hordenada la dicha limitación a cien años de Christiandad continua» ${ }^{13}$. Ese ambiente oficial de moderación, explica la buena acogida del libro que escribirá el dominico fray Agustín Salucio, un año después de la muerte de Felipe II.

Su Discurso acerca de la justicia y buen gobierno de España, en los estatutos de limpieza de sangre y si conviene, o no, alguna limitación a ellos (1599), manuscrito ${ }^{14}$ antes que libro, ha sido amplia y minuciosamente analizado por Albert Sicroff ${ }^{15}$ y por Israel S. Révah ${ }^{16}$. Como se aprecia en el título del tratado, Salucio no se pronuncia en contra de los estatutos. Fueron necesarios en el pasado debido al desfallecimiento en la fe de los conversos y su proclividad hacia la herejía. Pero este instrumento que evitaba el acceso a las instituciones de los conversos que judaizaban, al ir acompañado de normas que excluían sin límites a los descendientes de judíos, con el paso del tiempo había provocado una grave alteración del orden social. Bastaba un remoto descendiente o que

${ }^{12}$ Confessiones, Epistolae aliaque, 378-382.

${ }^{13}$ BNE, Ms. 3272: Discurso sobre la nobleza de España, circa 1622, fol. 5v.

${ }^{14}$ El citado Discurso fue, como indicamos, manuscrito (septiembre de 1598principios de 1599) antes que libro (como muy pronto, en mayo de 1599), y además, como otros libros, fue recogido por la Inquisición a finales de 1599. Y pese a todo ello es el texto que más se cita por parte de todos los tratadistas de limpieza de sangre. Sin lugar a dudas debió ser como manuscrito, lo cual prueba lo indicado por Fernando Bouza respecto a la permanencia y dinamismo de la escritura ad vivum -no obstante el gran desarrollo del libro- y el importante papel que sigue desempeñando en la difusión de materias controvertidas. Nunca mejor dicho, el Discurso en su forma no impresa, hace verídico el principio corre manuscrito: F. BouzA, Corre manuscrito. Una historia cultural del Siglo de Oro (Madrid, 2001).

${ }^{15}$ Sicroff, Los estatutos de limpieza de sangre, 222-246.

${ }^{16}$ I.-S. RÉvAH, «La controverse sur les statuts de pureté de sang. Un document inédit», Bulletin Hispanique 73 (1971), 263-306. 
una mínima parte de la parentela (un rebisabuelo de los dieciséis que se tienen) procediese o fuese de «mala casta», para que quedasen excluidos del acceso a instituciones de prestigio. Todo lo contrario sucedía con la «gente baxa y ordinaria», entre la que es imposible reconstruir la trayectoria de su linaje, y que resultaba mucho menos perjudicada que la «gente noble y onrada». Ciertamente, reconoce Salucio, alguno de los excluidos «por algún lado tiene raça de moro, judío, hereje o penitenciado», pero esa remota circunstancia no desmerece su cristiandad. Por tanto, el fraile dominico está exponiendo que, a la postre, los estatutos de limpieza de linaje han perjudicado claramente a los grupos sociales de mayor estatus, que comprueban con asombro cómo «las onras que se daban a sus abuelos, se les niegan a ellos y sus descendientes y se le dan comúnmente a gente desconocida». Los estatutos, al propiciar la calidad de la casta, cuando menos en las instituciones que los tienen, han hecho prevalecer esta distinción sobre la de más validez que otorga el ser; tal hecho ha acabado rompiendo el tradicional y armónico orden político, social y religioso de la sociedad castellana.

El análisis que al respecto hace Salucio -efectuado en tonos de hipótesis- es contundente:

No ay qué dudar, sino que los estatutos serían muy perjudiciales, si de ellos se siguieren notables detrimentos al Reyno, a los Príncipes, y a los vasallos; al Reyno en la religión y culto divino, en la paz de la República, y en el onor y reputación; a los Príncipes en la justicia y clemencia; y finalmente a los vasallos en el desengaño de los entendimientos y en el valor y virtud que les conviene ${ }^{17}$.

Salucio además sostiene que limpieza de sangre no es calidad exclusiva de un grupo de rasgos castizos, sino de la mayor parte de la nación; que ha disminuido considerablemente el número de los conversos que apostatan; y que no deben desaparecer los estatutos, pues aún quedan descendientes de judíos que pueden incurrir en apostasía. Ante tal situación, propone su actualización; en concreto, la limitación en la averiguación de la descendencia. No pone número de años exactos a su propuesta, sino que basta con imponer algún término - «que los estatutos fueran limitados a tal número de generaciones o años»-, con lo cual se evitaría que las

${ }^{17}$ A. SAlucio, Discurso acerca de la justicia y buen gobierno de España, en los estatutos de limpieza de sangre y si conviene, o no, alguna limitación a ellos, fol. 6r. 
indagaciones sobre limpieza queden al albur de la memoria, el capricho o la malevolencia de los testigos ${ }^{18}$. Y sostiene que si el monarca se decide por la reducción, ocurrirá un cambio de actitud en la sociedad, pues se evolucionará de la discordia y tensión social en torno a la limpieza a la amnesia en dicho tema. De forma que a «la limitación de los estatutos, se seguirá forçosamente dentro de pocos años otro semejante olvido» ${ }^{19}$.

\section{LOS PRIMEROS AÑOS DEL SIGLO XVII: ESTATUTOS Y ASCENDENCIA CONVERSA} COMO PROBLEMA POLÍTICO Y SOCIAL

El tratado de Salucio se imprimió (después del 4 de mayo de 1599 y antes del 11 de agosto de ese año ${ }^{20}$ y algunos ejemplares se entregaron a la institución más representativa del Reino de Castilla, es decir, sus Cortes, reunidas en Madrid el año $1599^{21}$. Para la institución era un tema trascendental, pues los estatutos inciden en el «seruicio de Dios, el del Rey, el bien del Reyno y la quietud dél y que en materia de Justicia y de Estado, es el casso, a que más deven advertir los ministros tan grandes como vuestra merced $»^{22}$.

Encargan las Cortes su examen a cuatro procuradores, los cuales tras tratarlo con teólogos y juristas ${ }^{23}$, en la reunión que tiene lugar el 8 de

${ }^{18}$ Ejemplo evidente de la manipulación de la memoria a través de los informes sobre limpieza de candidatos a plaza que requieren limpieza de sangre se puede encontrar en el reciente trabajo de B. CUART, «El juego de la memoria. Manipulaciones, reconstrucciones y reinvenciones de linajes en los colegios mayores salmantinos durante el siglo XVI», en S. De Dios y E. Torijano Pérez, eds., Cultura, política y práctica del derecho (Salamanca, 2012), 71-141.

${ }^{19} \mathrm{~S}$ ALucio, Discurso acerca de la justicia y buen gobierno de España, fol. 47v.

${ }^{20} \mathrm{La}$ fecha de impresión del libro, en torno a la cual existen diferentes opiniones, queda claramente sustanciada en el trabajo de RÉVAH, «La controverse sur les statuts de pureté de sang», 275-276.

${ }^{21}$ Actas de las Cortes de Castilla, tomo XVIII (Madrid, 1893), 548. Igualmente Domínguez OrTiz, La clase social de los conversos, 87-97; RévaH, «La controverse sur les statuts de pureté de sang», 277-278.

${ }^{22}$ BNE, Ms. 13043: Papel que dio el Reyno de Castilla a uno de los Señores Ministros de la Junta diputada para tratarse sobre el Memorial presentado por el Padre Maestro Salucio, en punto a las probanzas de la Limpieza y Nobleza del referido y demás Reynos, fol. 117.

${ }^{23}$ Los consultados fueron el jesuita Antonio de Padilla, el agustino Castroverde y el doctor Terrones, todos ellos teólogos, el licenciado Fernando Carrillo, y el fiscal de la contaduría mayor de Hacienda Juan Alonso Suárez. 
febrero de 1600, expresaron la obligación que tenía la institución de trasmitir al rey que "se sirviese de limitar la forma de los estatutos de limpieza destos reynos". Avalaban su opinión con las cartas escritas al Padre Salucio por el duque de Lerma, un Grande de España de la alcurnia del duque de Medina Sidonia, dos competentes hombres de Dios, como son el arzobispo de Valencia Juan de Ribera y el obispo de Pamplona, y dos teólogos, los maestros fray Pedro de Herrera y fray Tomás Coello.

Tras conocer el parecer de los procuradores, las Cortes pasaron a tratar sobre la materia de los estatutos. Hubo procuradores partidarios de la reforma, los cuales estuvieron encabezados por Pedro de Miranda, representante de la ciudad de Burgos. Inicia su discurso proclamando la virtud y letras de Salucio, y calificando su libro como «obra piadosa y de caridad», pero propone que se devuelva el libro a Felipe III, para que lo remita a tribunal o personas competentes, con el fin de que determinen lo más conveniente para el bien del monarca y del reino de Castilla. Del mismo parecer fue el procurador por Cuenca, Hernando Quiñones, representante de una ciudad con una amplia comunidad conversa ${ }^{24}$.

Pero quizás el discurso más destacado, debido a la personalidad de quien lo suscribe, sea el del condestable de Castilla, Juan Fernández de Velasco. Tiene un tono más moderado y preocupado exclusivamente por la defensa del orden estamental. No le parecía mal «ceñir la ejecución dellos [estatutos] a los límites que pusieron los estatuientes y reducilla a razón y términos de derecho, porque en las más partes deste Reyno se exceden los estatutos». En cambio, discrepaba del argumento propuesto por Salucio relativo a que si se retrocedía generacionalmente era rarísima la casa ilustre en la que, aun siendo bastantes de sus miembros cristianos, alguno de sus tatarabuelos no resultase moro o judío, pues contando treinta años por generación, veinte generaciones nos llevan seiscientos años atrás, época en la que eran minoría los cristianos en España. El condestable impugna la progresión aritmética aplicada por Salucio al cálculo generacional, no por razones de defecto matemático, sino por prácticas sociales. Claramente expresa que moros, indios y judíos se «sabe que con casarse todos, ninguno está fuera de su gente o nación y ralea», y que igualmente, sumando también a los cristianos viejos, «cada uno ama los de su familia y gente»; así como que el hecho

${ }^{24}$ P. L. CADARSO, «Esplendor y decadencia de las oligarquías conversas de Cuenca y Guadalajara», Hispania 186 (1994), 53-94. 
de los posibles matrimonios mixtos entre cristianos viejos y otras gentes, los impide la «desemejanza y diversidad de la gente y las costumbres y la calidad y la condición y no dando esta mezcla y frequencia de casamientos queda frustrada la conclusión y effecto de la cuenta como está dicho en los ejemplos de arriba». Por consiguiente, buena parte del discurso lo dedica a demostrar la falsedad del principio matemático con el que Salucio quiere probar que prácticamente ninguna familia estaba libre de tener mancha en su linaje. Lo verdaderamente importante es que el condestable estaba defendiendo la superioridad de su estamento dentro de la sociedad de órdenes, y dentro del primer orden, de los grandes sobre los hidalgos. Con el fin de mantener esta posición preeminente, estaba justificado expulsar del estamento aristocrático al noble que tenga defecto o mácula a causa de la sangre procedente de gente impura. Su argumentación bien vale la pena recogerla:

porque aunque sea verdad que la desigualdad ordenada forma y conforma la policía del mundo, pero no la desigualdad desordenada: bien tolera y aún quiere la República que en la nobleza aya más y menos grados, de manera que la mano es de maiores usos y más hermosa por ser los dedos entre si desiguales, mucho honrran este Reyno que en los naturales dél aya grandes y títulos y caballeros y escuderos y como puede una mano ser mejor que otra también es licito que entre los grandes sea de más estima el que muestra más antigüedad, más hombres bellicosos, mejores y más iguales casamientos, pero si concurre en un grande sin culpa ni demérito suio alguno destos defectos que le hagan inferior a el y a sus succesores al más vil de los del ínfimo y esto sin límite ${ }^{25}$.

Frente a estas posiciones moderadas, Pedro de Villamizar, procurador por León, encabeza otra más rigorista. Su voto enlaza claramente con los fervorosos defensores de una Castilla limpia por razones de unidad política, fidelidad en el servicio a la Monarquía y conservación y defensa de la pureza religiosa; además reprocha al dominico que tanta preocupación como siente por las personas que padecían a causa de su estirpe, la debe tener también hacia la sangre noble y limpia de los antiguos linajes ${ }^{26}$. Recojamos un párrafo de

\footnotetext{
${ }^{25}$ Actas de las Cortes de Castilla, Tomo XIX (Madrid, 1899), 33-39.

${ }^{26}$ AHN, Sección Órdenes Militares, Libro 1320. «Discurso que hizo Juan Fernández de Velasco, Condestable de Castilla contra el primer punto del libro de fray Agustín
} 
su encendido voto, que demuestra perfectamente su posicionamiento inexorable sobre los manchados. Tras ensalzar las virtudes del hombre noble y limpio, arquetipo social indisociable para muchos de los cristianos viejos puros, alerta contra el daño que podría hacer una limitación en las medidas precautorias contenidas en los estatutos, ya que «le paresce que podría ser puerta por donde entrase la Heregía o judaísmo en Hespaña, lo cual Dios no permita, ni el Reyno sea causa y principio de tan no esperado mal» ${ }^{27}$.

El parecer de los procuradores en Cortes, a la postre, verificaba lo que apuntaba Salucio respecto a la escisión social. Por un lado, se encuentran algunos destacados miembros de la sociedad castellana, tanto civiles como eclesiásticos, que desean poner límites a las probanzas de limpieza de sangre ya que originan grandes convulsiones en familias en las que aparecía un manchado, mientras que otras, por el miedo a ser tiznados, no competían en pos de las honras. Del otro lado, otra parte de la sociedad se inclinaba por defender y reforzar el arquetipo social en el que confluía «limpieza y nobleza», calidades distintas, pero imprescindibles, para alcanzar los honores ${ }^{28}$. Quienes realmente aspiraban a tener una condición social importante, necesitaban de ambas calidades, y precisamente esas calidades no se le reconocían al que provenía por algún costado de estirpe judía, aunque su cristiandad estuviera fuera de dudas.

Si la monarquía hubiera llevado a la práctica las recomendaciones del libro de Salucio, parte del tema de la limpieza de sangre se hubiera resuelto. En concreto, aunque la limpieza continuara efectuándose para acceder a instituciones, si se hubiera reducido el tiempo de la investigación sobre genealogías a cien años o tres generaciones, se hubiera impedido que

Salucio sobre la limitación de los estatutos».

${ }^{27}$ Actas de las Cortes de Castilla, tomo XIX (Madrid, 1899), 35-36.

${ }^{28} \mathrm{El}$ o los autores del «Papel que dio el Reyno de Castilla», aunque opuestos totalmente a esas ideas y defensores de una nobleza que se obtuviese por la virtud y del acceso a instituciones con estatuto de personas que hubieran probado la limpieza de su linaje en cien años, aún siendo de ascendencia judía, nos hacen el siguiente retrato de la realidad social: «Porque en España ay dos géneros de Noblezas. Una mayor que es la Hidalguía, y otra menor, que es la limpieza, que llamamos christianos viejos. Y aunque la primera de la Hidalguía, es más onrrado de tenerla; pero muy más afrentoso es faltar la segunda: porque en España, más estimamos a un hombre pechero, y limpio, que a un Hidalgo que no es limpio», BNE, Ms. 13043, fol. 117v. 
el tiempo inmemorial facilitase el encontrar defecto o sangre manchada, especialmente en los que más fácil era conocer sus ascendientes. No fue así. A descendientes de judíos conversos, auténticos y fieles cristianos y buenos súbditos de la monarquía, se les continuará negando el acceso a las instituciones de estatuto.

Probablemente, hubo circunstancias que retardaron la solución respecto al tema de la limpieza de sangre, como el hecho de que la propia sociedad siguiera obsesionada por la cuestión de la limpieza; que las cabezas más representativas de la cultura sabia y, sobre todo, las autoridades políticas estuvieran más preocupados por «el número de enemigos moriscos» ${ }^{29} ; \mathrm{y}$ que prosiguiera el influyente peso de los rigoristas o intransigentes ${ }^{30}$.

De todos modos, sería injusto no reconocer que en el bando de los partidarios de la reforma había destacadas instituciones, como el Consejo de la Inquisición, que a través de una «Relación y Consulta» del inquisidor general Niño de Guevara se mostró a favor de la limitación y moderación, es decir, «quitar los excesos y abusos, daños y enconvenientes... de su estrecha y rigurosa obseruancia» ${ }^{31}$; o bien personalidades tan destacadas, y ya mencionadas, como el duque de Lerma que, según el provincial de la orden agustina, padre Calahorrano, había leído el Discurso de Salucio dos veces y «nunca había visto cosa que tanto contentamiento le diese» ${ }^{32}$.

Pero, posiblemente, lo que faltó fue lo que recomendó el procurador por Zamora, García de Ledesma, en la sesión que las Cortes dedican al estatuto el 8 de febrero de 1600. No era otra cosa que Felipe III «como señor de todo provea lo que más convenga» ${ }^{33}$. El monarca no ejerció su poder absoluto en este tema, aunque le rodeaba un entorno favorable a la publicación del libro de Salucio y a su propuesta de limitar el tiempo de la probanza.

\footnotetext{
${ }^{29}$ En el «Papel que dio el Reyno de Castilla», fol. 121v, su o sus autores, claramente recomiendan al Príncipe que la «prudencia» aconseja encontrar los medios para recuperar al vasallo fiel, cuya única rémora es ser descendiente o tener algún pariente judío, y a continuación, en contraposición con esa tolerancia hacia el descendiente de judío, señala: «y debe advertirse mucho, que tiene España en medio de tanto número de Henemigos moriscos».

${ }^{30}$ Domínguez Ortiz, La clase social de los conversos, 71-72.

${ }^{31}$ RÉvaH, «La controverse sur les statuts de pureté de sang», 289-296.

${ }^{32}$ RÉVAH, «La controverse sur les statuts de pureté de sang», 297.

${ }^{33}$ Actas de las Cortes de Castilla, tomo XIX (Madrid, 1899), 38.
} 
Felipe III, siguiendo la propuesta de las Cortes, envía el Discurso a una Junta ${ }^{34}$, que se reúne en Valladolid el 30 de julio de 1601. En su dictamen se apartan de las tesis reformistas, pues opinan que «por buen gouierno y estado conuendrá no dar lugar a que se imprima y recoger lo que lo están». Y todo ello, no obstante que en el margen del papel que se envía a la Junta para que se constituya y decida, va la siguiente frase, que parece dictada por el válido Lerma: «Olgaré que la Junta resuelva esto con la más brebedad que pudiere» ${ }^{35}$.

No conocemos la respuesta final que emite la Junta. Pero sí que el monarca, el valido, la Inquisición, y una parte muy representativa del alto clero que estaba a favor, no tuvieron el suficiente empuje y poder decisorio para sacar adelante la publicación de un libro que servía de apoyo ideológico a la limitación de los estatutos y a una revisión de lo que se entendía por cristiano nuevo o neófito. Más peso tuvieron, en cambio, los opositores, los rigoristas, encabezados por el Consejo de Estado, y una amplia parte de la sociedad que tenía como prenda de honor su limpieza y como motivo unos sentimientos imbuidos de un lejano antijudaísmo, trasladado ahora al neocreyente.

Tras el verano del año 1601, el tema queda olvidado por el reino. Prueba fehaciente de ello, es que la limpieza de sangre ya no es tratada por las Cortes que se vuelven a reunir el año 1602 en Valladolid ${ }^{36}$. Pero no por ello las voces de los partidarios de la reforma estatutaria dejan de escucharse. El año 1605, de nuevo otro jesuita, el padre Ignacio de las Casas, de origen morisco, dirige un interesante memorial al papa Clemente VIII (1592-1605), que ha sido estudiado con minuciosidad por parte de Francisco de Borja Medina y Youssef El Alaoui ${ }^{37}$.

${ }^{34}$ La forman Juan de Idiáquez, el conde de Miranda, el Cardenal de Sevilla, fray Gaspar de Córdoba, el obispo de Valladolid, Juan Ocón, y Francisco Contreras.

${ }^{35}$ Archivo General de Simancas, Estado, leg. 1847: Consulta a la Junta mandada hacer por Vuestra Majestad sobre la impresión del libro de que ha compuesto fray Agustín Salucio de la orden de Santo Domingo (Valladolid, 30 de julio de 1601).

${ }^{36}$ La inacción de la corte y la no inclusión del tema de la limitación en las Cortes a pesar de los favorables pronunciamientos de buena parte de lo que podríamos llamar sociedad «culta», motiva que Révah presente los hechos como una manifestación del poder que tenía en España el «mythe de la pureté raciale».

${ }^{37}$ F. DE B. Medina, «La Compañía de Jesús y la minoría morisca», Archivum historicum Societatis Iesu 57 (1988), 3-134; MedinA, «Precursores de Vieira», 517518; Y. El Alaou, Jésuites, Morisques et Indiens. Étude comparative des méthodes 
El escrito del padre Ignacio de las Casas enlaza en algunas cuestiones con el del dominico fray Agustín de Salucio, cuyo memorial conoce. De las Casas tampoco es partidario de una total supresión de los estatutos, propone soluciones evangélicas para acoger a los nuevos cristianos, y se muestra a favor de moderar el tiempo en que es preciso probar que se es cristiano viejo: «que no se pudieren llamar ni tener por christianos nueuos los que passassen cien años después del bautismo de sus pasados». Pero, también hay propósitos en los que va más allá que Salucio. Pretende concluir con la contraposición de identidades entre cristianos viejos y nuevos, y para ello solicita la «igualación» al Papa, como ha señalado Francisco de Borja Medina. ¿Por qué esta igualación? Porque el punto de partida que crea y construye identidades es erróneo, ya que ocurre que familias sin honor, y a veces con mancha, cubren con «oro el nuevo tronco de su descendencia», y, en cambio, otras familias de «cepa [que] de puro viejo estaban podridas», tienen una identidad deslegitimada a causa de la infamia y la sospecha. En fin, de haberse tenido en cuenta la opinión de de las Casas, la invención y falsificación de linajes, la infamia lanzada sobre otros, o bien el desconocimiento que se tenía de muchas estirpes -lo que permitía ocultaciones-, hubiera dejado de ser un elemento de disensión social y de perjuicio para aquellos que por su ascendencia familiar eran considerados cristianos nuevos.

3. Nuevas PROPUESTAS EN TORNO AL DEBAte DE LOS ESTATUTOS Y LA EXCLUSIÓN DE LOS CRISTIANOS NUEVOS TRAS LA EXPULSIÓN DE LOS MORISCOS: EL MEMORIAL DE JUAN DE MONTEMAYOR

No deja de ser significativo que concluida la expulsión de los moriscos, es decir, resuelto de forma expeditiva otro episodio de intolerancia, relacionado igualmente con una identidad desvirtuada del neocreyente morisco, vuelva a reaparecer el tema de los estatutos y con el mismo, la controversia sobre quién es verdaderamente el cristiano nuevo ${ }^{38}$.

d'évangélisation de la Compagnie de Jésus d'après les traités de José de Acosta (1588) et d'Ignacio de Las Casas (1605-1607) (Paris, 2006), especialmente págs. 100-104, y 212-214.

${ }^{38}$ Quizás este ambiente tendría que ver con las medidas tomadas por la monarquía respecto a los conversos portugueses: J. I. Pulido Serrano, «Las negociaciones con los 
En concreto, dos de los mejores conocedores coetáneos de los hechos, los cronistas reales Luis Cabrera de Córdoba y Gil González de Ávila, en las referencias que hacen al tema de la limpieza de sangre no aportan noticias hasta después de la expulsión de los moriscos. En el caso del último cronista, cita el memorial elaborado por Juan de Figueroa Gaytán, regidor de Toledo por el bando de los caballeros, entre los años 1586 y $1616^{39}$, que hemos buscando, infructuosamente hasta el momento, en el fondo «Cartas» del Archivo Municipal de Toledo ${ }^{40}$.

Figueroa no es converso; sin embargo, por su rama materna, arrastra la infamia del compromiso que el linaje contrajo con las Comunidades, de ahí su obsesión por lavar la afrenta poniéndose al servicio de la Corona. Pero, sobre todo, toma tal partido ya que es un regidor vinculado al bando cortesano -como ha señalado Francisco José Aranda, encabezado por sus allegados los Dávalos y los Vaca de Herrera-, a la facción lermista del regimiento toledano, más preocupado por estar «al servicio de Su Majestad» que por el servicio a la república. Movido por el servicio a la monarquía, Figueroa considera que, una vez expulsados los moriscos y concluida su perjudicial presencia dentro de la sociedad cristiana - cessó el daño-, de nuevo debe revisarse la cuestión de los estatutos de limpieza ${ }^{41}$.

Por su parte, el cronista Luis de Cabrera, gran conocedor y anotador de los hechos ocurridos en la corte, relata que el 26 de julio de 1614, se estaba tratando de reformar los estatutos en los cabildos catedrales y órdenes militares en lo referente a limpieza y nobleza de linajes -como se

cristianos nuevos en tiempos de Felipe III a la luz de algunos documentos inéditos (15981607)», Sefarad 66 (2006), 345-376.

${ }^{39}$ F. J. ARANDA, «Nobles, discretos varones que gobernáis a Toledo. Una guía prosopográfica de los componentes del poder municipal en Toledo durante la Edad Moderna», en F. J. Aranda, ed., Poderes intermedios, poderes interpuestos. Sociedad y Oligarquía en la España Moderna (Cuenca, 1999), 227-309.

${ }^{40}$ Deseamos agradecer al director del Archivo Municipal de Toledo, don Mariano García Ruipérez la colaboración que nos ha prestado en la búsqueda del citado memorial.

${ }^{41}$ «Don Juan de Figueroa Gaytán, Regidor de la ciudad de Toledo, en vn memorial que presentó en su ilustrísimo Ayuntamiento, suplicándole pida al Reyno en Cortes suplique a su Magestad Filipe Tercero mande poner remedio en los muchos inconuenientes que resultan del modo de platicar los Estatutos de limpieza; y si con la expulsión de los moriscos cessó el daño, que cesse también la ley». La existencia de tal memorial la recoge G. GonZÁlez dE ÁvILA, Theatro eclesiastico de las Iglesias Metropolitanas y Catedrales de los Reynos de las dos Castillas (Madrid, 1645), tomo I, 329. 
aprecia de nuevo aparecen vinculadas como dos calidades sociales necesarias-, de forma que haya menos rigor que hasta aquí para quien tenía que acceder a estos beneficios ${ }^{42}$.

La noticia que nos da el cronista, coincide de lleno con la presentación de un tratado anónimo al rey Felipe III, en el que nuevamente se plantea la reforma de los estatutos y los límites de la exclusión social que pende sobre el cristiano nuevo.

El tratadista, aunque anónimo como se ha dicho, tiene nombre para la amplia mayoría de los expertos en el tema. Se trata del jesuita Juan de Montemayor (1549-1641), provincial de la orden en Castilla entre 15981602 y entre 1614-1618. A él le encargará el valido Lerma y el inquisidor general Bernardo de Rojas -que según Montemayor deseaban «hazer limitación de los estatutos para toda España»- la redacción de un memorial copioso ${ }^{43}$ que justifique la generalización en todos los reinos de la monarquía del memorial, presentado el año 1613, por Diogo Sánchez de Vargas, en que solicitaba que se moderara la aplicación de los estatutos en el reino de Portugal.

Difícilmente se puede poner en duda que, como venimos diciendo, el autor del memorial no sea Montemayor. Más aún, cuando el bien informado Gil González de Ávila escribe, sin dudar, que había leído el citado memorial en su versión impresa ${ }^{44}$, en una edición muy limitada: unos 30 ejemplares, que mandó imprimir el Cardenal de Toledo e inquisidor general, Bernardo de Sandoval ${ }^{45}$. Todo parece indicar que no quedan ejemplares de esa edición y que tenemos que seguir recurriendo al manuscrito. En

${ }^{42}$ L. CABrera de CóRdoba, Relaciones de las cosas sucedidas en la corte de España, desde 1599 hasta 1614 ([Madrid, 1857] Valladolid, 1997; prefacio R. García Cárcel), 561.

${ }^{43}$ El citado memorial apenas ha sido analizado, pues Albert Sicroff y Julio Caro Baroja lo desconocen; Domínguez Ortiz hace una breve alusión al mismo, y el cuidadoso análisis que preparaba Israel S. Révah no vio la luz, debido a la temprana muerte de este investigador; sin embargo en uno de sus trabajos, le dedica una par de lucidas páginas: I. S. RÉvaH, «Gil González de Ávila et les statuts de pureté de sang», en Studia hispanica in honorem Rafael Lapesa (Madrid, 1974), vol. II, 493-518. De todos modos las primeras y más fiables noticias sobre dicho memorial nos las ofrece J. E. DE URIARTE, Catálogo razonado de obras anónimas y seudónimos de autores de la Compañía de Jesús (Madrid, 1904-1916), núm. 2061 (vol. II, 179) y 4471 (vol. III, 463).

${ }^{44}$ G. GonZÁlez de Ávila, Historia de la vida y hechos del ínclito monarca, amado y santo D. Felipe Tercero (Madrid, 1771), 212.

${ }^{45}$ URIARTE, Catálogo razonado de obras, vol. II, 179. 
nuestro caso, hemos utilizado el escrito que en la Biblioteca de la Universidad Complutense de Madrid, aparece rotulado como «Parecer sobre los estatutos de limpieza de sangre en España... Informe dirigido al Rey (Felipe III?), sin autor, atribuido a Juan de Montemayor». Todo nos hace pensar que es el manuscrito realizado por Montemayor, pues coincide exactamente con el comienzo que le asigna José Ignacio de Uriarte en su Catálogo sobre obras anónimas y seudónimas que tienen por autores a la Compañía de Jesús.

Si importante es conocer exactamente quién pudo ser el autor del memorial, mucho más es su contenido. Está en la línea de lo escrito por el padre Salucio. Sin embargo, ahonda más en dos cuestiones claves para justificar la limitación en la demostración de la limpieza.

- Primera: actitud más condescendiente hacia el cristiano nuevo que desciende de hebreos, pues tiene «agora España mejor estado de la fe en los descendientes de judío» y sus rasgos de identidad se han desvinculado de los de sus predecesores.

- Segunda: necesidad de reformar los estatutos, por motivos de conveniencia política, pues la disputa entre quien se dice cristiano viejo y al que quieren hacer cristiano nuevo, perjudica a la conservación y reputación de la monarquía.

El comienzo de su memorial es claro en cuanto al fin que propone: limitar el tiempo durante el que se debe probar la limpieza de un candidato y sus descendientes por parte de padre y madre, es decir, por ambas líneas. Con tal fin y para que su propuesta no parezca ex novo, hace relación a Felipe III de anteriores proyectos propuestos por papas y reyes sobre limitación en la averiguación de las ascendencias. Pero, sobre todo, incide en que se dan nuevas actitudes y nuevas formas de vivir la religión en los que descienden de judíos, o han emparentado con ellos. Por todo ello, como cristianos que son, y no tanto cristianos nuevos, debe revisarse su acceso a las instituciones que han establecido estatuto y tener las mismas oportunidades, sin que lo que influya sea el linaje, sino la preparación para ocupar el beneficio:

Muchas vezes se a tratado de limitar los estatutos que hai en España de limpieza, y es cosa zierta, que la santidad de Pio quinto y Gregorio XIII tuvieron ia ordenadas bullas, en que los limitauan a plazos bien moderados y que el Rey Don Phelipe nuestro señor y el Padre de Vuestra Majestad que sea en gloria, en los últimos años de su gouierno con grande acuerdo de sus consejeros, tuvo ordenada la dicha limita- 
zión, a zien años de christiandad continua, la qual no se publicó, por que el cielo (o lo que se pueda creer) tiene guardada la resoluzión de este negozio, que tanta vezes se a consultado para Vuestra Majestad, como le guardó la expulsión de los moriscos, de la qual tantas vezes se auía tratado, sin poder resolver, y porque he entendido que al presente se ha tornado a mouer esta plática y dado memoriales a Vuestra Majestad y en razon de esto, y atento que el estado de España en lo que toca a la fee los descendientes de herejes, moros y judíos es mui diferente aora que en el tiempo en que se hizieron los estatutos, porque entonzes comúnmente todos eran sospechosos en la fee, y ahora comúnmente son seguros en ella, como abajo se berá, a parecido dar este memorial en el qual se prueua que combiene limitar los dicho estatutos, de manera que los descendientes de herejes, moros y judíos, de los quales en lo que toca a su fee ai toda sastisfaczión y seguridad que son de corazón cristianos... sean capazes de las honrras que los demas christianos viejos concurriendo en ellos todas las partes de letras, bondad y prudencia o fortaleza que para tales honrras se requieren ${ }^{46}$.

Como acabamos de leer, todo ello requiere de una nueva pedagogía respecto a quién es en esos momentos el excluido, cómo se comporta y qué beneficios puede suponer para la monarquía y el Reino reducir a tres generaciones la demostración de que se es limpio. En síntesis, como se insiste a lo largo del manuscrito, más condescendencia por parte del cristiano viejo, revisión de la categoría y principios sustantivos con los que se asemeja al nuevo cristiano, y valoración de los beneficios que de todo ello obtendría tanto la Corona como la sociedad.

Mediante el consabido estilo de pregunta / respuesta, y apoyándose en las Sagradas Escrituras, los Padres de la Iglesia y autores favorables a la limitación de las pruebas, desde Mauroy hasta Salucio, Juan de Montemayor acomete con gran acierto la redacción de un memorial en el que lo novedoso no es la propuesta, sino sus justificaciones.

Tolerancia no es un concepto que exista en el siglo XVII, pues todavía tardará en desarrollarse este ideal moral vinculado a la persona ${ }^{47}$, pero sí que es cierto, como dice Italo Mereu, que se puede hallar una idea y una actitud similar, consistente en soportar determinadas ideas, personas o

${ }^{46}$ Biblioteca de la Universidad Complutense de Madrid (BUCM), BH-127, «Parecer sobre los estatutos de limpieza de sangre en España... Informe dirigido al Rey (Felipe III?)», fols. 1-2.

${ }^{47}$ D. A. J. Richards, Toleration and the Constitution (Oxford, 1989). 
cosas cuando, por necesidades contingentes o históricas, no es posible eliminarlas ni siquiera con la fuerza del Derecho ${ }^{48}$. Precisamente, ni el derecho canónico, ni el civil, contenían disposiciones sobre el hecho de que el nuevo bautizado se viera privado de acceder a oficios en instituciones por la circunstancia de su reciente conversión. Desde el momento que se recibían las aguas bautismales, los nuevos cristianos eran tan cristianos y tenían los mismos derechos espirituales y civiles que los descendientes de los que, supuesta y altivamente, nunca perdieron su condición de cristianos, por haberse encerrado sus antecesores en las montañas del norte peninsular. De todos modos, la realidad indicaba que al cristiano nuevo se le estaban negando derechos, y que había una actitud de intemperancia expresada por Montemayor a través de las expresiones: azepcion de persona y excluido. La pretensión del memorialista en materia de condescendencia encuentra su principal apoyo en la virtud teologal de la caridad y en la actitud que comporta la misma: el amor al prójimo. El objetivo principal es que no exista «ninguna diferenciación» entre el cristiano viejo y el nuevo, de forma que todos sean admitidos a cualquier oficio, honor o dignidad eclesiástica o seglar.

Entre los argumentos que se manejan, están el ya mencionado de que no se excluya por razón de raza o casta y que, en su lugar, se valore para ocupar un cargo a quien «posee la nobleza moral de las virtudes y costumbres... pues es cosa más noble el nazimiento spiritual que no el carnal»; el que impere entre los cristianos la caridad para que formen todos «un mismo cuerpo místico de la Iglesia», y para poner fin al odio, enemistad y murmuraciones; que por la misma virtud no se recuerde la ascendencia de la que proceden los cristianos nuevos, pues mantenerla «fresca en la memoria» hace que algunos apostaten; y que la limpieza que exige Dios a quienes ocupan oficios en las iglesias no es la limpieza de sangre, sino la «limpieza de la mancha de pecados, del zelo de las almas y la caridad».

La nueva identidad comienza con una nueva imagen religiosa del neocreyente, que como sostiene Montemayor, «biben tan cristianamente como los demás cristianos viejos». Pero tan importante como ello, es que desaparezca el discurso relativo a su origen, a su pertenencia a una estirpe «mala y perversa», y que una ininterrumpida e irreversible cadena genética es la responsable de tal circunstancia. La novedosa identidad que el jesuita

${ }^{48}$ I. Mereu, Historia de la intolerancia en Europa (Barcelona, 2003), 32-33. 
perfila en el neocreyente de origen judío, comienza por la absolución de su permanente culpabilidad de deicida. Continúa deshaciendo el silogismo o deducción referente a que el origen del linaje determina actitudes y hábitos inicuos; por el contrario, provienen de una genealogía que comienza en Abraham, prosigue con los profetas y acaba con los discípulos y el mismísimo Jesús; por tanto, su identidad no puede ser la propia de los hijos del Demonio. Y alcanza su punto culminante cuando Montemayor integra al neocreyente en la sociedad de órdenes cristiana, colocándolo por encima del labrador, que es «de menos genio y partes»; hecho, por cierto, que parece estar poniendo fin al triunfo del villano propio del siglo anterior. Incluso va más allá, colocándolo por encima del noble desviado, es decir, el noble cargado de «pecados y malos ejemplos». Por el contrario, el nuevo cristiano y su identidad, vinculada como se ha expuesto a una fe segura, ha de servir de ejemplo pues «aiudara a salbar muchas almas».

Montemayor completa la serie de argumentos que justifican la limitación del periodo de tiempo durante el que debe demostrarse la limpieza, exponiendo ventajas políticas para la monarquía y el reino. En primer lugar, se podría contar con los mercaderes «ricos de esta nazión», es decir, los financieros - no lo expresa, pero debe estar refiriéndose a los grandes financieros de la «nación» portuguesa, que precisamente son el punto de salida de este copioso memorial- que al percatarse que la Corona no cuenta con ellos, se marchan a otros reinos, arrastrando a familiares y amigos de la «nación» que ejercen igual profesión. Igualmente, se podría poner fin a los perjuicios que los estatutos ocasionan a todo el Reino, comenzando por la nobleza, por el mundo de los privilegiados, el de los mejores, muchas de cuyas casas ven empañado su honor por haber emparentado con personas que «tienen raza». También se podría resolver la contrariedad de más envergadura que afecta a toda la sociedad, tal como venía indicando desde años antes Salucio, la «guerra cibil» que la dividía en dos bandos, caracterizados por la «presunción», en el caso de los cristianos viejos, y el «coraje», en el de los neófitos. En definitiva, las informaciones resultaban cada vez un problema de mayor envergadura, pues el «número de los tocados crece cada día como la espuma, porque en el linaje donde una vez entra la raza, jamás puede salir, ni purificarse en todos sus descendientes».

A estos graves problemas internos de la sociedad había que agregar otro de carácter externo, igualmente indicado con anterioridad con Salucio: la extendida idea entre los europeos de que toda la «nazión española» 
estaba infectada por el linaje judío.

Cuántas disfunciones, pues, se podrían evitar si la monarquía decidiese reducir el tiempo en que era necesario probar la limpieza, ya que de seguir haciéndose como hasta entonces el interminable viaje a través del linaje, no resultaba difícil encontrar algún descendiente con la única mancha de la «raza». Esa no había sido la razón del establecimiento de los estatutos. La que los había motivado, al menos en la opinión de Montemayor, ya estaba resuelta y, por tanto, se podía poner límite a los estatutos, pues a la altura de la segunda década del siglo XVII, los que antes «eran en España sospechosos en la fe... agora, comúnmente hablando son seguros» ${ }^{49}$.

Como ocurre tras la publicación del memorial de Salucio, aunque ahora no llega a existir un procedimiento tan reglado como en los años 1599 y 1600, es la voz del Reino, la de las Cortes, la que se vuelve a escuchar, aunque con bastante menos peso y unanimidad de los diputados respecto al problema.

El cronista real Gil González de Dávila expone con meticulosidad la súplica que en las Cortes de 1618 hace Gaspar Cimbrón, procurador por la ciudad de Ávila, a Felipe III. Cimbrón, hombre que había probado la limpieza y nobleza de su sangre, pues era caballero de la Orden Militar de Santiago, no por ello renunciaba a revisar el principio de la sangre pura en la que se atrincheraba el cristiano viejo para sacar ventajas sociales; es decir, era partidario de poner fin a aquel engaño de los entendimientos como ya había indicado el padre Salucio.

En la intervención que protagoniza Cimbrón, en la sesión que tiene lugar el 26 de febrero de 1618, dirá que no está en contra de los estatutos, pero desea «que la práctica de ellos sea sin ofensa de Dios, y del próximo». Por tanto, pone el énfasis en la revisión de la forma en que se realizan las pruebas, pues han hecho que informaciones dadas por buenas en realidad sean malas, y a la inversa, otras dadas por malas resultan buenas. La situación es tan compleja, y a la vez causa tantos problemas a la sociedad, que al igual que hiciera dieciocho años antes el procurador García de Ledesma, Cimbrón vuelve a solicitar que el asunto lo coja entre sus propias manos el monarca, es decir, «el que tiene por su cuenta el gobierno de estos reynos». El monarca, actuando como dicta la razón

\footnotetext{
${ }^{49}$ BUCM BH-127, «Parecer sobre los estatutos de limpieza», fols. 65-66.
} 
de Estado, argumento que será principal en los inmediatos memoriales a favor de la moderación de los estatutos, debe procurar la reforma de los mismos, con el fin de evitar la conmoción social y las perturbaciones que están causando la averiguación de las calidades del linaje y la forma de vivir la religión.

Cimbrón, finalmente, propone una posible solución o remedio que acabe con todo lo que enturbia la realización de las pruebas de limpieza, como son los memoriales sin firma, perjurios, sobornos y agravios. No es muy amplio en la exposición de su solución, pero sí que contiene el principio que será clave en las futuras propuestas reformistas: que se establezca «algún punto fixo a la nobleza y limpieza... y qué actos positivo bastaran» para demostrar que se tienen las calidades precisas ${ }^{50}$.

La opinión de Cimbrón no cala entre los restantes procuradores. La mayor parte de sus compañeros de Cortes estimaron que era peligroso pronunciarse de forma que no fuese la habitual. No en vano, sobre los que no compartían posiciones tradicionales recaía la sospecha de tener linaje manchado y de ser partidario de una religión apartada de la ortodoxia. Lo cual suponía perder reputación u honra, así como recibir la acusación de que exponían a la comunidad de fieles católicos a la asimilación de los principios de otras confesiones. Por ello estaban en contra de cualquier apertura en materia de sangre limpia. El 13 de marzo de 1618 resolvieron e hicieron conocer a Felipe III,

que ninguna cosa ha habido en España tan a propósito para conservar la pureza, calidad y grandeza de sangre de sus naturales, como el haber establecido en estos reinos los estatutos de limpieza y nobleza, con que ha sido Dios servido de conservar no solo esta calidad, sino la religión cristiana y culto divino que es lo principal, sin las mezclas y inconvenientes que se ven en otras naciones; y le toca mucho al reino junto en Cortes que representa los estados de la república, suplicar a Su Majestad se sirva amparar los estatutos en la fuerza, vigor y observación que ahora están ${ }^{51}$.

\footnotetext{
${ }^{50}$ Actas de las Cortes de Castilla, tomo XXXI (sesión 26 de febrero de 1618), 343346.

${ }^{51}$ Actas de las Cortes de Castilla, tomo XXXI (sesión 13 de marzo de 1618), 266.
} 


\section{Conclusión}

Resulta innecesario cualquier análisis tras la lectura del último texto. Felipe III y el Reino estaban en una situación de parálisis final, de modo que ni siquiera la Junta para la reforma de los estatutos de limpieza que piden las Cortes el año 1619 llega a constituirse. No se podía abrir ningún camino hacia la resolución de una cuestión que perdía al Reino, pero que el propio Reino prefería conservar como «piedra de escándalo», antes que moverla con el limitado hecho de acortar los tiempos que eran precisos para demostrar la limpieza o evitar los abusos y arbitrariedades que se cometían contra candidatos a oficios en instituciones con estatuto ${ }^{52}$, especialmente a los que se consideraba que eran cristianos nuevos.

El peso social de los rigoristas, de los partidarios de no redefinir en sus contenidos la imagen del converso, resultaba de tal fuste que, como decía el arbitrista y abogado Martin González de Cellorigo, era muy difícil desencantar aquella república de hombres encantados, que viven fuera del orden natural. Tan difícil, que la fecunda generación que a partir de 1620 intenta reconstruir nuevamente qué es ser cristiano nuevo, fracasa nuevamente, a pesar de haberse apoyado en ideales religiosos irénicos y tardíos humanistas, en la razón de estado «administrativa»-orientada principalmente a resolver las contingencias que perjudican a la monarquía-, en una cultura jurídica que quería establecer lo que representaba ser cristiano nuevo, y en unos pensadores que creían que el Derecho natural, el derecho justo, no puede excluir a cristianos por parte de otros cristianos ${ }^{53}$.

${ }^{52}$ Fue la única medida que finalmente se toma para evitar los abusos y vicios que acompañaba a la realización de las pruebas de limpieza. Felipe III como transacción para que las Cortes acepten pagar el impuesto de los 18 Millones, aceptará la petición del Reino -mediante una pragmática dada el 28 de junio de 1619- de prohibir la admisión de memoriales que no estuviesen firmados por sujeto conocido por parte de consejo, tribunal, chancillería, audiencia, colegio, universidad o congregación seglar; el firmante quedaba sujeto, además, a probar lo que su subscribía en su escrito (Actas de las Cortes de Castilla, tomo XXXIV, 310-311. «Pragmática de S. M. Para que ninguno de los consejos, audiencias, y jueces inferiores de S. M. admitan memoriales sin firma». Felipe III, Belem de Portugal, 25 de junio de 1619). La norma también afectará a cabildos eclesiásticos y cofradías, pues el monarca solicita un breve de similar contenido al papa Pablo V (Actas de las Cortes de Castilla, tomo XXXIV, sesión 15 de julio de 1619).

${ }^{53}$ J. HeRnÁndeZ Franco, «Les intellectuels espagnols du XVII ${ }^{\mathrm{e}}$ siècle face à l'opinion majoritaire de la société vieille-chrétienne», en CARrasco, Molinié, Pérez, dirs., La 
De nada, o de muy poco, valieron las decisiones políticas de Olivares y sus colaboradores, o los memoriales de Roco Campofrío, Salazar, Valdés, Serrano de Silva, Torreblanca, Ceballos, Peñalosa o Murcia de la Llana. Sus propuestas fueron derrotadas por el argumentario de los rigoristas como Adán de la Parra, Gavilán Vela, Escobar del Corro, Jiménez Patón, posteriormente Torrejoncillo, Contreras, Félix de Amín, Diego del Castillo, o a principios del siglo XIX, por los defensores, dentro de la España liberal, de los valores tradicionales de los españoles cristianos viejos. No extraña nada que el año 1913, Pío Baroja, en su obra El árbol de la Ciencia, en buena medida obra descriptiva de una España que mira con recelo a Europa, ponga en boca del doctor Iturrioz la siguiente afirmación, que deja claro lo difícil que resulta exonerar al converso y desprenderlo de su origen: «El doctor Iturrioz, tío carnal de Andrés Hurtado, solía afirmar, probablemente de una manera arbitraria que en España desde el punto de vista moral hay dos tipos: el tipo ibérico y el tipo semita. Al tipo ibérico asignaba el doctor las cualidades guerreras y fuertes de la raza; al tipo semita las tendencias rapaces, de intriga y comercio».

Recibido: 23/10/2012

Aceptado: 16/12/2012

pureté de sang en Espagne, 315-339; A. IRIGOYEN LÓPEZ, «Religión católica y estatutos de limpieza de sangre. A propósito de un Memorial al Conde-Duque de Olivares», Sefarad 70 (2010), 141-170; R. LÓPEZ VelA, «Antijudaísmo, pruebas de limpieza y la pragmática de actos positivos de 1623», en Rivero RodríGuez, coord., Nobleza hispana, nobleza cristiana, vol. I, 795-830. 